\title{
MAPEAMENTO DO USO E COBERTURA DA TERRA DO ALTO CURSO DO RIO SANTO ANASTÁCIO UTILIZANDO IMAGENS MULTIESPECTRAIS LANDSAT 8
}

Carolina Gomes de Melo

Curso de Graduação em Engenharia Ambiental e Sanitária

Faculdade de Engenharia de Presidente Prudente/UNOESTE e-mail: difonzo.carol@gmail.com

Ireli Cristina Luz

Curso de Graduação em Engenharia Ambiental e Sanitária

Faculdade de Engenharia de Presidente Prudente/UNOESTE

e-mail: irelisoma@yahoo.com.br

Lucas Prado Osco

Pós-Graduação em Agronomia

UNOESTE - Universidade do Oeste Paulista e-mail: pradoosco@gmail.com

\section{Ana Paula Marques Ramos}

Docente do Programa de Pós-Graduação em Meio Ambiente e

Desenvolvimento Regional

UNOESTE - Universidade do Oeste Paulista

e-mail: anaramos@unoeste.br 


\section{RESUMO}

Os recursos naturais e o meio ambiente da Terra estão em mudanças contínuas em resposta à evolução natural às atividades antrópicas. Assim, o mapeamento do uso e cobertura da terra consiste em uma ferramenta de apoio à diversos projetos na área ambiental, tal como planejamento e recuperação de áreas degradadas. O objetivo desse trabalho é mapear o uso e cobertura da terra de uma importante região do Pontal do Paranapanema, no extremo oeste do Estado de São Paulo, a bacia do alto curso do Rio Santo Anastácio. Esta bacia é utilizada como manancial para abastecimento público do município de Presidente Prudente - SP. O método aplicado nesse trabalho está dividido em três grandes fases, as quais contemplam sete etapas: download dos dados vetoriais e raster para a área da bacia; preparação da base cartográfica vetorial; pré-processamento da imagem multiespectral; elaboração da chave de interpretação; classificação da imagem orbital; validação da classificação; e elaboração do mapa de uso e cobertura da terra. A classificação da imagem Landsat 8, sensor OLI, foi realizada no QGIS 2.14 aplicando o método supervisionado por pixel. Para avaliar o resultado da classificação, utilizou-se a matriz de erros e o índice kappa. O mapa temático produzido no QGIS 2.14 apresentou as seguintes classes: corpo d'água, floresta arbórea (mata), floresta herbácea arbustiva (pastagens), cultura e solo exposto, as quais foram definidas na chave de interpretação. A partir do mapa de uso e cobertura foi possível quantificar a extensão territorial de cada uma dessas classes na bacia hidrográfica. Os resultados permitem concluir que somente $28,6 \%$ da área da bacia é coberta por vegetação e que 45,2 \% por áreas de pastagens e 15,2 \% solo exposto. Conclui-se que a área da bacia se encontra com fortes indícios de degradação ambiental, apontando para a necessidade de estudos futuros que investiguem a qualidade ambiental da área em função de outros parâmetros, tais como a qualidade das águas superficiais e subterrâneas da bacia.

Palavras chave: Mapa temático; classificação de imagens; bacia hidrográfica; análise ambiental. 


\section{INTRODUÇÃO}

Os recursos naturais e o meio ambiente da Terra estão em mudanças contínuas em resposta à evolução natural às atividades antrópicas, e se deve atentar a essas mudanças em busca do monitoramento e medidas de planejamentos dos fenômenos que causam estes acontecimentos. Hoje, devido aos constantes avanços tecnológicos podese observar a Terra ou qualquer parte dela por meio de satélites, com o uso de imagens de Sensoriamento Remoto.

O Sensoriamento Remoto é uma tecnologia que permite obtenção de informações da superfície terrestre, através da captação da energia refletida e emitida da superfície, alimentado por tecnologias dos satélites orbitais (FLORENZANO ,2011). A confiabilidade e a rapidez no processo de sensoriamento permite uma maior facilidade na aquisição dos dados que são de grande importância para o mapeamento de uso e ocupação do solo de uma determinada área de estudo, sendo uma maneira eficaz e viável de coletar dados para monitorar e modelar uma determinada região, especialmente em países de grande extensão territorial, como o Brasil. Através de softwares de Sistema de Informação Geográfica (SIG), pode-se realizar a classificação de imagens orbitais e a elaboração de mapas temáticos, os quais facilitam a interpretação e análise da qualidade ambiental de uma determinada área. Assim esses produtos, seja de uma área especifica, ou mais global, permitem planejamentos eficazes, diagnósticos eficientes, propostas de soluções de custos mais baixos e criação de alternativas inteligentes para os desafios enfrentados junto às mudanças crescentes que se observa na natureza principalmente com a interferência antropológica.

Segundo Richards e Jia (2006), a técnica de classificação de imagens visa rotular o pixel de uma imagem de acordo com suas características espectrais. Esse processo é realizado atribuindo cada pixel, ou conjunto de pixels da imagem, a uma determinada classe de uso e (ou) cobertura da terra. Tais regiões são atribuídas às classes de informação, por algum método de classificação, utilizando um software de SIG, tal como o QGIS, o SPRING, o ArcGIS.

Os softwares de SIG aperfeiçoam a aplicação de ferramentas de Geoprocessamento, as quais são caracterizadas por permitirem, dentre outras, a integração de dados cartográficos de diferentes fontes e formatos, tal como vetoriais e matriciais (raster), podendo ter como produto final um documento cartográfico, do tipo 
mapa temático. As imagens orbitais, um tipo de dado raster, são produtos do Sensoriamento Remoto e viabilizam o mapeamento de grandes áreas em extensão territorial, tal como é caracterizada a região do Pontal do Paranapanema, a qual é caracteriza por apresentar sete grandes bacias hidrográficas, dentre as quais a bacia do Rio Santo Anastácio, a qual comtempla a área de estudo do presente trabalho. A extensão territorial da região do Pontal, localizada no extremo oeste do Estado de São Paulo, é de aproximadamente 19 mil $\mathrm{km}^{2}$ e é composta por 32 municípios. A área de estudo do presente trabalho é a bacia do alto curso do Rio Santo Anastácio, abrangendo parte dos municípios de Presidente Prudente, Pirapozinho, Regente Feijó, Anhumas e Álvares Machado. Esta é caracterizada uma importante área dentro da bacia do Santo Anastácio e, também do Pontal do Paranapanema, por tal trecho do rio ser utilizado como manancial para abastecimento público do município de Presidente Prudente, comportando um reservatório de acumulação na confluência do Rio Santo Anastácio com o Córrego do Cedro. Na Figura 1 é apresentado a localização geográfica das bacias hidrográficas presentes no Pontal, bem como destacado a área de estudo.

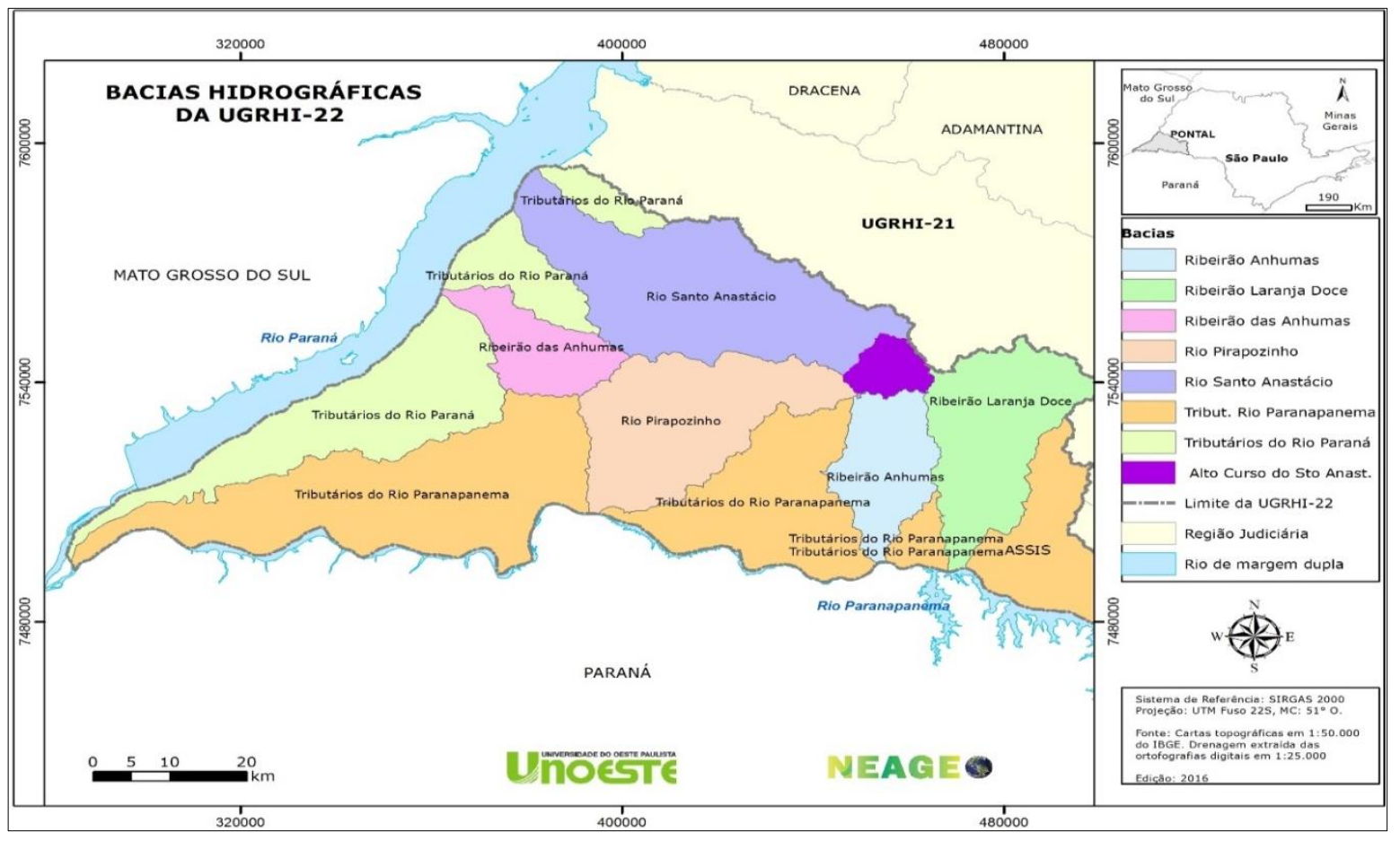

Figura 1: Localização das bacias hidrográficas do Pontal do Paranapanema.

O objetivo desse trabalho é mapear o uso e a cobertura da terra da bacia hidrográfica do alto curso do Rio Santo Anastácio. Essa região do Pontal do Paranapanema, além de ser caracterizada por abranger o manancial do alto curso do 
Rio Santo Anastácio, que é utilizado como manancial para abastecimento público do município de Presidente Prudente, também é caracterizada por ser uma região que passou por um intenso processo de urbanização devido à expansão e criação de conjuntos habitacionais, aumento da agricultura, entre outros. Nesse sentido, a análise ambiental dessa bacia, em termos do seu uso e ocupação, insere-se como uma importante ferramenta que permite interpretar a real situação da sua área, permitindo planejar ações no sentido de se restabelecer as condições de equilíbrio e sustentabilidade em torno do manancial.

\section{MATERIAIS E MÉTODOS}

O método está dividido em três grandes fases, as quais contemplam sete etapas: download dos dados vetoriais e raster para a área da bacia; preparação da base cartográfica vetorial; pré-processamento da imagem multiespectral; elaboração da chave de interpretação; classificação da imagem orbital; validação da classificação; e elaboração do mapa de uso e cobertura da terra. Os equipamentos e softwares utilizados foram QGIS 2.14, base vetorial de dados cartográficos(municípios do Estado de São Paulo, malha rodoviária e dados de hidrografia), disponíveis gratuitamente em banco de dados do IBGE (Instituto brasileiro de Geografia e Estatística), e dado raster (imagem multiespectral do satélite Landsat 8, sensor OLI), disponível gratuitamente na base de dados da USGS $^{1}$ (United States Geological Survey - Levantamento Geológico dos Estados Unidos).

\section{Pré - Processamento dos dados}

Essa primeira fase contempla quatro etapas: download dos dados; preparação da base cartográfica; pré-processamento da imagem e elaboração da chave de interpretação. A aquisição dos dados cartográficos, no formato vetorial, foi realizada no banco de dados do IBGE. A aquisição da imagem multiespectral, sensor OLI, do satélite Landsat 8, foi obtida na base da USGS para a data de 09 de março de 2017.

A etapa de preparação da base cartográfica vetorial correspondeu a aplicar ferramentas de Geoprocessamento no QGIS 2.14, do tipo conversão dos dados para o

\footnotetext{
${ }^{1}$ http://earthexplorer.usgs.gov/
} 
sistema de referência SIRGAS 2000 e sistema de projeção UTM (Universo Transverso de Mercator) fuso 22 Sul, e recorte dos dados vetorial para a área de estudo. A etapa de pré-processamento da imagem orbital consistiu em preparar a imagem para o processo de classificação. Os tratamentos foram reamostragem da imagem de 16 para 8 bits, reprojeção da cena o Hemisfério Sul, SIRGAS 2000 UTM 22 Sul, correção radiométrica e correção do ângulo solar, conforme recomendações da USGS (2016), manipulação de contraste e composição de bandas, na cor natural $\mathrm{R}(4) \mathrm{G}(3) \mathrm{B}(2)$ e falsa cor $(\mathrm{R}(6) \mathrm{G}(5) \mathrm{B}(4)$. Para cada uma desses processamentos foi utilizada a literatura pertinente. Na Figura 2, tem-se a imagem a ser classificada representada na composição natural, e na Figura 3 a combinação falsa cor.

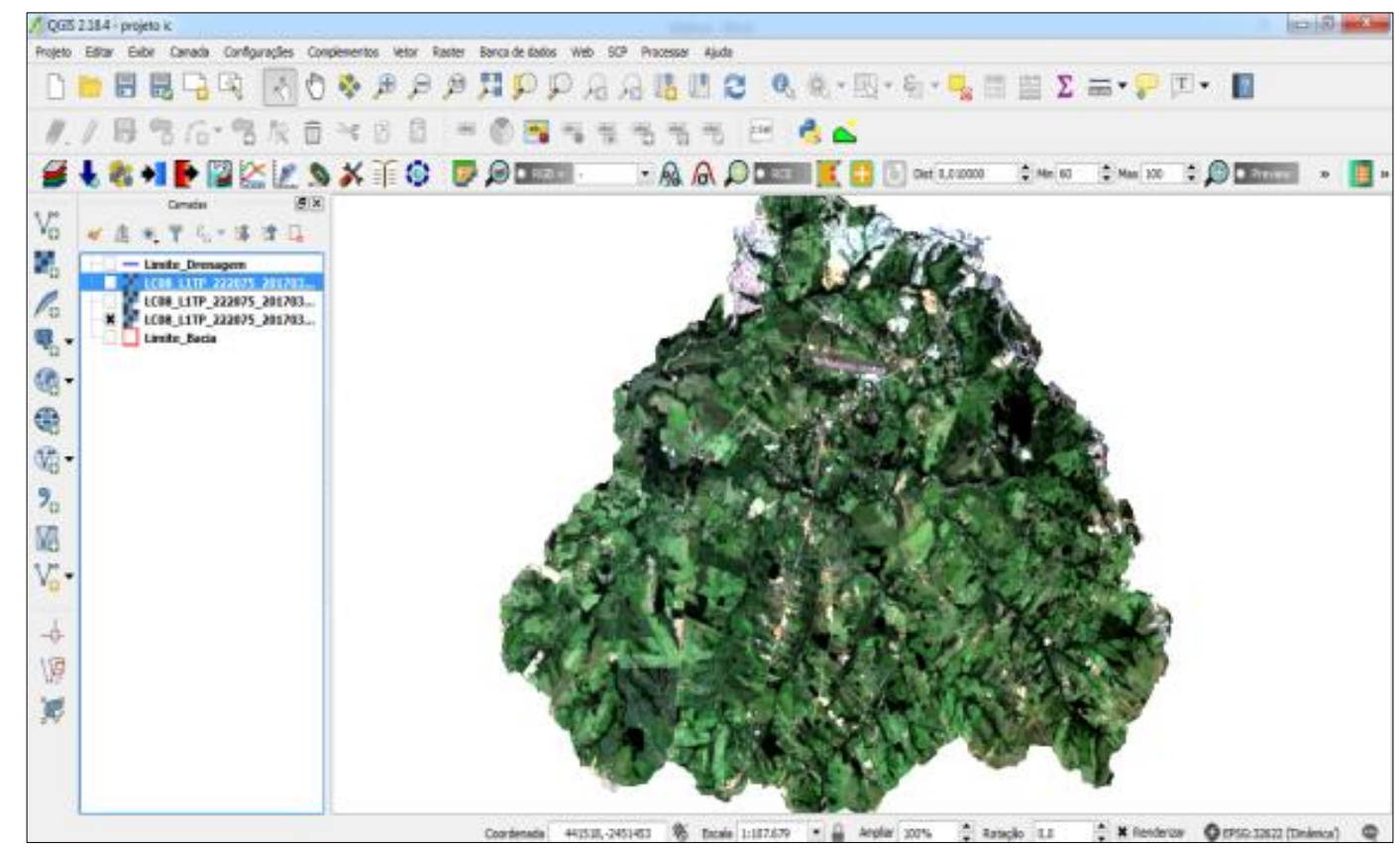

Figura 2: Combinação de bandas RGB 432 (cor natural). 


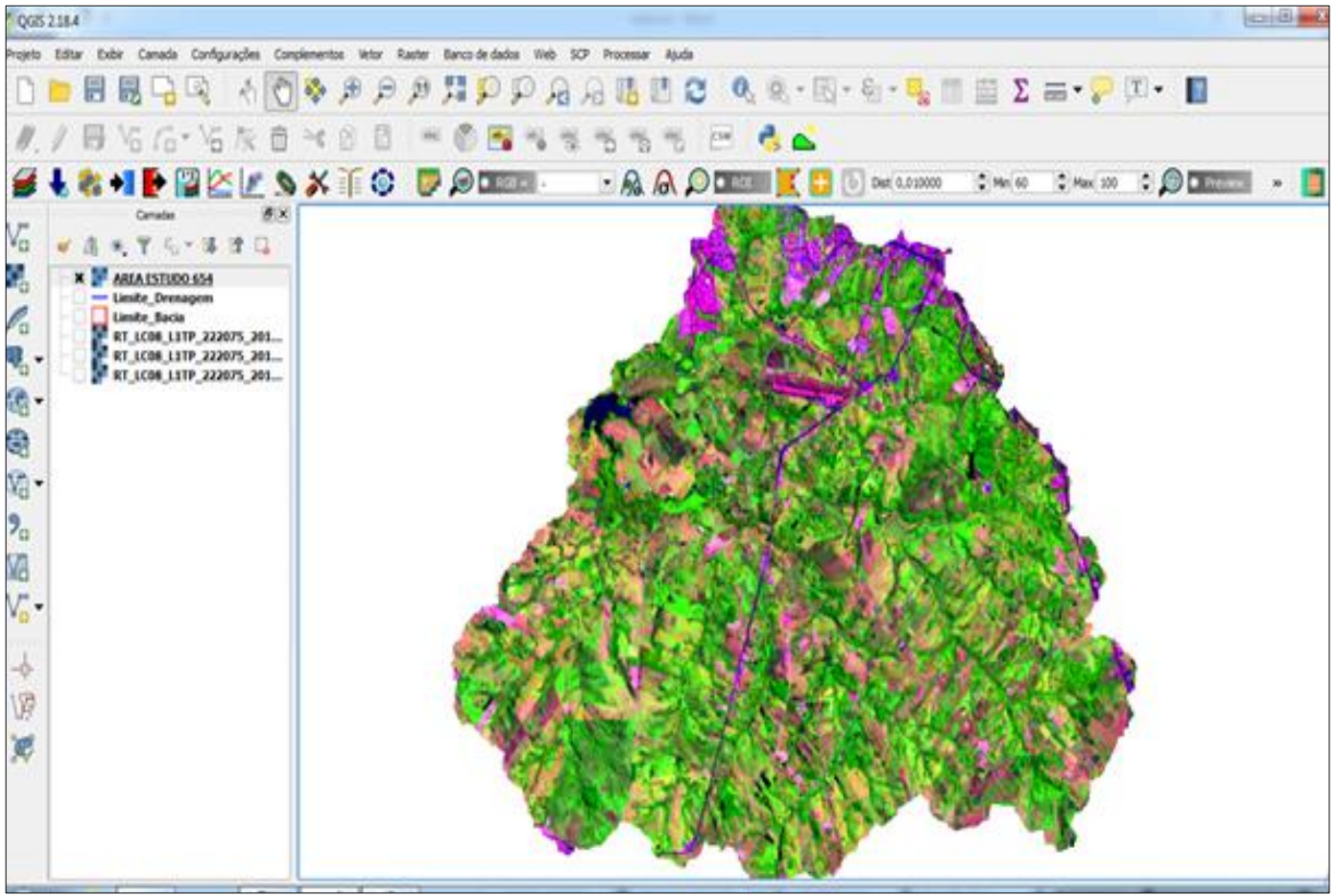

Figura 3: Combinação de bandas RGB:654 (falsa cor)

\section{Processamento dos dados:}

A fase de processamento dos dados foi dividida em três etapas: elaboração da chave de interpretação, classificação da imagem orbital e validação da classificação. A chave de interpretação consiste na análise visual dos elementos presentes na imagem (tonalidade, cor, textura, forma, tamanho, padrão e outros), determinando as categorias temáticas presentes na imagem, tais como mata/cerrado, cultura, pastagem, solo descoberto e água (ROSA, 2009). No estudo de caso, foram identificadas 5 (cinco) classes temáticas, sendo: Corpos d'água, Floresta Arbustiva, Floresta Herbácea (pastagem), área urbana e Cultura.

Para a classificação da imagem Landsat 8 foi utilizado o complemento (plugin) "Semi-Automatic Plugin(SCP) do QGIS e o método aplicado foi o supervisionado por pixel padrão do programa. Para avaliar o resultado dessa classificação, foi analisada a matriz de erros e o valor do índice kappa, ambos disponibilizados automaticamente pelo QGIS em um arquivo .txt no término do processo de classificação.

\section{Produção do mapa temático.}

A elaboração do mapa temático de uso e cobertura da terra da bacia do alto curso do Rio Santo Anastácio foi realizada no QGIS. O mapa apresentou as cinco 
classes definidas na chave de interpretação. No processo de produção do mapa, aplicouse os conceitos da Cartografia temática para favorecer a comunicação cartográfica.

\section{ANÁLISE DOS RESULTADOS}

O mapa de uso e ocupação do alto curso do rio Santo Anastácio obtido por meio de técnicas de Geoprocessamento aplicadas em imagem de Sensoriamento Remoto, é apresentado na Figura 4. O valor do índice Kappa foi de 95\%. Este produto cartográfico possibilita uma análise sistêmica da área da bacia hidrográfica em estudo. De acordo com o IBGE (2006), os estudos das formas e da dinâmica da ocupação da terra são instrumentos de grande importância para a construção de indicadores ambientais e para a avaliação da capacidade ambiental, diante das diversas atividades empregadas na produção, pois o conhecimento fornecem subsídios para as analises e avaliações dos impactos ambientais.

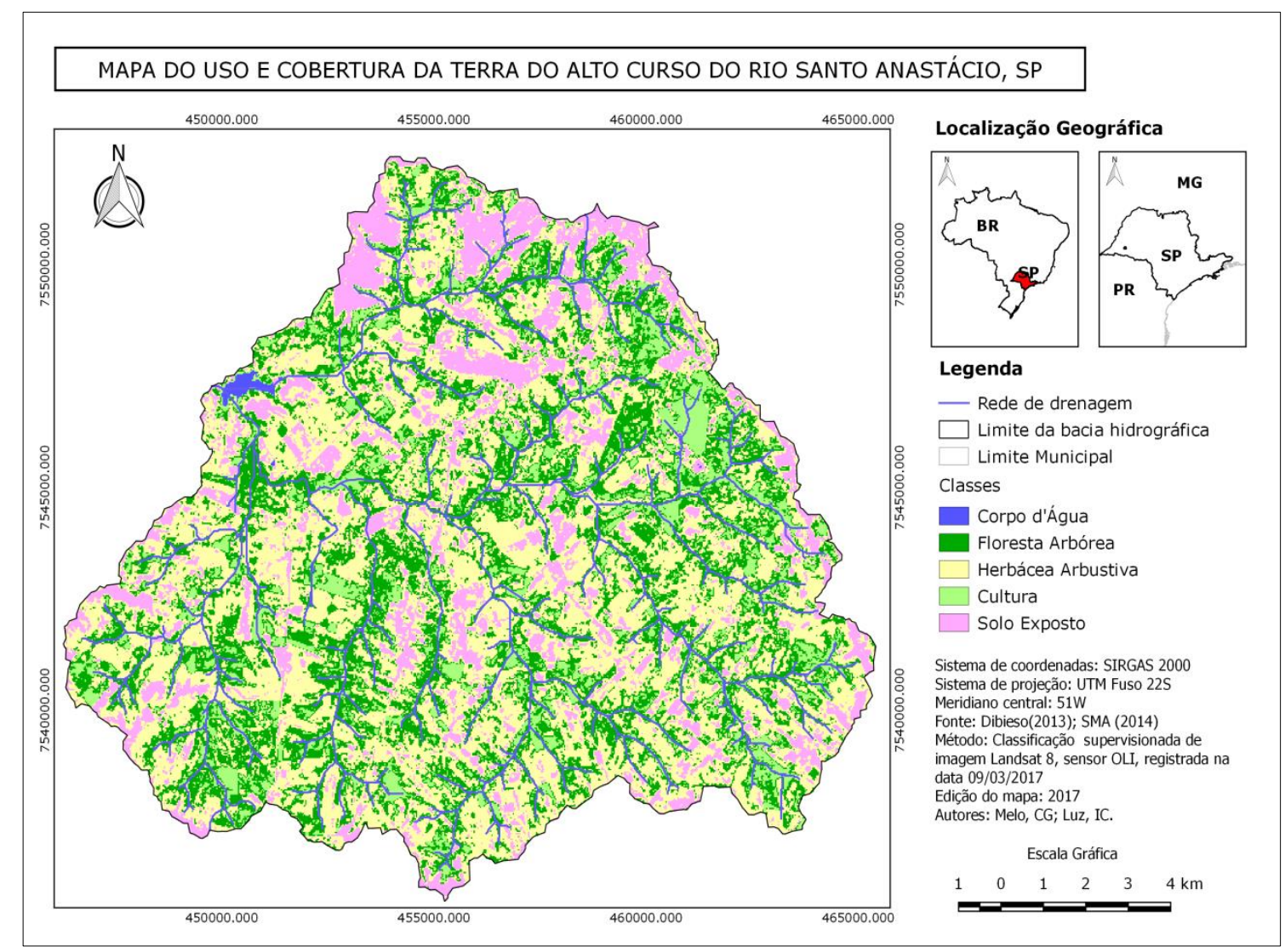

.Figura 4: Mapa de uso e cobertura da terra da bacia hidrográfica do alto curso do rio Santo Anastácio. 
A avaliação quantitativa das classes temáticas representadas no mapa de uso e cobertura é apresentado na tabela 1. Verificou-se que o uso da terra predominante do alto curso do rio Santo Anastácio corresponde a classe herbácea arbustiva (pastagens) 45,2\%. Isto se deve a atividade marcante na região que é o pastoreio, porém são necessárias práticas conservacionistas e bom manejo para que não ocorram elevadas perdas do solo.

Tabela 1: Quantificação das classes temáticas do mapa de uso e cobertura da terra.

\begin{tabular}{|c|c|c|c|}
\hline Classe & $\begin{array}{l}\text { Extensão da na } \\
\text { bacia em } \mathbf{m}^{2}\end{array}$ & $\begin{array}{l}\text { Extensão } \\
\text { da na } \\
\text { bacia } \mathrm{Km}^{2}\end{array}$ & $\begin{array}{l}\text { Porcentagem } \\
\text { da área da } \\
\text { bacia }\end{array}$ \\
\hline Corpo d'água & $475.363,90$ & 0,475 & $0,2 \%$ \\
\hline Floresta Arbórea & $56.348628,7$ & 56,348 & $28,6 \%$ \\
\hline Herbácea Arbustiva & $89.492656,57$ & 89,492 & $45,2 \%$ \\
\hline Cultura & $21.210413,23$ & 21,210 & $10,7 \%$ \\
\hline Solo Exposto & $30.129788,58$ & 30,12 & $15,2 \%$ \\
\hline TOTAL & 197. 656851 & 197,656 & $100 \%$ \\
\hline
\end{tabular}

As áreas de floresta arbórea (Mata/Cerrado) abrangem 28,6\% do total da área da bacia, e na imagem orbital são observadas ao longo dos percursos dos rios, morros, encostas e área de reserva. Na classificação não foi realizada a separação de classes mata e cerrado, por apresentarem tonalidades e texturas semelhantes. O foco do presente estudo de caso não foi o de classificar o tipo de vegetação na bacia, e sim a área de arborização que abrangem principalmente os entornos da bacia. A arborização tem o papel fundamental em proteger as margens dos cursos d'água possibilitando a melhoria da qualidade da água, pois retém o excesso de sedimentos, evita o deslizamento de terras e assoreamento dos rios, além de umedecer o solo, servir como habitat natural para grandes quantidades de espécies de animais como pássaros, mamíferos e repteis atuando também como corredores ecológicos e fixação de gás carbônico.

A análise da Figura 4 e Tabela 1 permite identificar que a abrangência de cultura na área da bacia é de 10,7\%, sendo representadas pela lavoura de cana-de açúcar, definida como cultura temporária, e das lavouras dos pequenos agricultores da região. Segundo IBGE, são culturas cujo ciclo vegetativo não excedem um ano e 
após sua produção, o terreno fica disponível para um novo plantio. O volume de corpos d'água disponível é de apenas $0,2 \%$, ou seja, um tanto preocupante levando em consideração que é o principal manancial de abastecimento de água da cidade de Presidente Prudente, portanto medidas para a proteção dessa bacia devem ser constantemente postas em prática.

\section{CONCLUSÕES}

A partir do mapa de uso e cobertura e da quantificação da extensão territorial de cada uma das classes temáticas encontradas na bacia hidrográfica do alto curso do Rio Santo Anastácio, foi possível realizar um diagnóstico preliminar na qualidade ambiental dessa área do Pontal do Paranapanema. Os resultados permitem concluir que somente menos de um terço da área da bacia é coberta por vegetação e que a classe de uso predominante é a pastagem. Esse cenário aponta que a bacia se encontra com fortes indícios de degradação ambiental, o que ressalta a necessidade de estudos futuros que investiguem a qualidade ambiental da bacia em função de outros parâmetros, como a qualidade de suas águas superficiais e subterrâneas. Os resultados desse trabalho servem de subsídio para outros trabalhos na região da bacia que visem à proteção do meio ambiente. 


\section{REFERÊNCIAS}

FLORENZANO, T.G. Iniciação em Sensoriamento Remoto. 3 ed. São

Paulo: Oficina de Textos, 2011. 101 p.

IBGE. Instituto Brasileiro de Geografia e Estatística. Rio de Janeiro. Disponível em: $<$ http://www.ibge.gov.br >.

RICHARDS, J. A.; JIA, X. Remote Sensing Digital Image Analysis. 4th Edition Berlin-Heidelberg: Springer-Verlag, 2006. 439 p.

ROSA, R. Introdução ao sensoriamento remoto. $7^{\circ}$ ed., Uberlândia: EDUFU, 2009

United States Geological Survey (Levantamento Geológico dos Estados Unidos) USGS. Disponível em: 〈http://earthexplorer.usgs.gov/〉. 